\title{
The Long-Term Outcomes of Intensive Combined Therapy of Adult Patients with Localised Synovial Sarcoma
}

\author{
Katarzyna Kozak ${ }^{1, *}$, Paweł Teterycz ${ }^{1}$, Tomasz Świtaj ${ }^{1}$, Hanna Koseła-Paterczyk ${ }^{1} \oplus$, \\ Sławomir Falkowski ${ }^{1}$, Tadeusz Morysiński ${ }^{1}$, Ewa Bartnik ${ }^{2,3}{ }^{\mathbb{D}}$, Anna M. Czarnecka ${ }^{1,4}{ }^{1}$, \\ Michał Wagrodzki ${ }^{5}$, Iwona Ługowska ${ }^{1,6}$ and Piotr Rutkowski ${ }^{1}$ (D) \\ 1 Department of Soft Tissue/Bone Sarcoma and Melanoma, Maria Sklodowska-Curie National Research \\ Institute of Oncology, 02-781 Warsaw, Poland; pawel.teterycz@pib-nio.pl (P.T.); \\ tomasz.switaj@pib-nio.pl (T.Ś.); hanna.kosela-paterczyk@pib-nio.pl (H.K.-P.); sfalkowski@coi.waw.pl (S.F.); \\ tmorysinski@coi.waw.pl (T.M.); anna.czarnecka@gmail.com (A.M.C.); iwona.lugowska@pib-nio.pl (I.Ł.); \\ piotr.rutkowski@pib-nio.pl (P.R.) \\ 2 Institute of Genetics and Biotechnology, Faculty of Biology, University of Warsaw, 02-106 Warsaw, Poland; \\ ewambartnik@gmail.com \\ 3 Institute of Biochemistry and Biophysics, Polish Academy of Sciences, 02-106 Warsaw, Poland \\ 4 Department of Experimental Pharmacology, Mossakowski Medical Research Centre, \\ Polish Academy of Sciences, 02-106 Warsaw, Poland \\ 5 Department of Pathology and Laboratory Medicine, Maria Sklodowska-Curie National Research Institute of \\ Oncology, 02-781 Warsaw, Poland; michal.wagrodzki@pib-nio.pl \\ 6 Early Phase Clinical Trials Unit, Maria Sklodowska-Curie National Research Institute of Oncology, \\ 02-781 Warsaw, Poland \\ * Correspondence: katarzyna.kozak@pib-nio.pl
}

Received: 24 August 2020; Accepted: 24 September 2020; Published: 28 September 2020

\begin{abstract}
Introduction: Synovial sarcoma (SaSy) is a high-grade, malignant soft tissue sarcoma (STS) accounting for $5-9 \%$ of STS. The aim of this study was to analyse outcomes of patients with localised SaSy treated in a single institution with a uniform neo- and adjuvant-combined therapy protocol. Methods: 171 patients with stage II/III SaSy were treated between 1997 and 2014. Chemotherapy consisted of 4 cycles of ifosfamide $12 \mathrm{~g} / \mathrm{m}^{2}$ and two cycles of a doxorubicin-based regimen $75 \mathrm{mg} / \mathrm{m}^{2}$. With the exception of patients who underwent amputation, all patients received neoadjuvant radiotherapy. Results: Median age was 33 years (range 17-69). Tumours larger than $5 \mathrm{~cm}$ in size were found in $70 \%$ of patients. The 5-year overall survival (OS), local relapse-free survival (LRFS) and metastasis-free survival (MFS) rates were $75 \%, 80 \%$ and $60 \%$, respectively. In multivariate Cox's regression, age $>35$ years, male sex, larger tumour size and histology other than monophasic were associated with worse OS. Conclusions: In adult patients with localised SaSy, long-term survival can be achieved in a significant proportion of cases with intensive combined therapy. The multivariate analysis identified age, sex, disease stage and histology subtype as independent prognostic factors of OS.
\end{abstract}

Keywords: synovial sarcoma; neoadjuvant; adjuvant; chemotherapy; radiotherapy; prognostic factors

\section{Introduction}

Synovial sarcoma (SaSy) is a high-grade malignant mesenchymal tumour which accounts for 5-9\% of all soft tissue sarcomas (STS) [1-4]. SaSy typically affects adolescents and young adults [5-7]. There are three main histologic SaSy subtypes: monophasic, biphasic and poorly differentiated. In over $95 \%$ of cases of SaSy, the specific chromosomal translocation $t(X ; 18)$ (p11.2; q112) is present [8-10]. 
In most cases, this translocation results in rearrangements of the SYT gene with the SSX1 or SSX2 genes [8]. The most common primary tumour site is the lower limb [4,7,11]. Metastatic lesions at the initial diagnosis are present in approximately $18 \%$ of patients [12]. Prognostic factors in patients with SaSy are not well defined. In retrospective analyses, the following are mentioned among factors negatively affecting the prognosis: large primary tumour size, grade 3 tumour, monophasic subtype, male sex, older age at onset, non-extremity location, SS18-SSX1 fusion and resection R1 $[2,5,6,11,13-16]$. The strongest evidence exists for an association between primary tumour size and clinical outcome $[2,3,5,7,11,15,17,18]$. Wide surgical resection combined with perioperative radiation therapy (RT) is the cornerstone in the treatment of patients with localised SaSy. The role of adjuvant chemotherapy in adult patients with SaSy is not well established. However, according to recently published National Comprehensive Cancer Network (NCCN) and European Society of Medical Oncology (ESMO) guidelines, adjuvant chemotherapy should be considered in high-risk localised STS patients [19,20]. The lung is the most common site of initial recurrence after treatment [4]. Disease recurrence occurs most commonly within 2 years after primary tumour resection, although late relapses after 10 years have been noted [21].

The aim of this study is to evaluate the efficacy, safety and prognostic factors in patients with localised SaSy treated with a uniform neo- and adjuvant-combined therapy protocol.

\section{Materials and Methods}

This prospective study included 171 (96 female, 75 male) patients with locally advanced SaSy treated in the Department of Soft Tissue/Bone Sarcoma and Melanoma at the Maria Sklodowska-Curie National Research Institute of Oncology (MSCNRIO) between 1997 and 2014. The study group comprised adult patients with a primary tumour, after an unplanned tumour excision ( $\leq 12$ weeks earlier) and with clinical local recurrence. The eighth edition of the American Joint Committee on Cancer (AJCC) classification was used for disease staging. All pathological diagnoses were confirmed in the Department of Pathology, MSCNRIO. In all patients, perioperative chemotherapy was applied according to a uniform scheme following a multidisciplinary evaluation. Preoperative chemotherapy consisted of 2 cycles of ifosfamide at a dose of $1.7 \mathrm{~g} / \mathrm{m}^{2} /$ day on days $1-7$ in a cycle of every 21 days. After surgery, patients were administered 2 cycles of doxorubicin, $20 \mathrm{mg} / \mathrm{m}^{2} /$ day, with cisplatin $35 \mathrm{mg} / \mathrm{m}^{2} /$ day on days $1-3$ in a cycle of every 21 days, and 2 cycles of ifosfamide with the same regimen as in the preoperative setting. Excepting patients who underwent limb amputation, patients received preoperative $5 \times 4$ Gray (Gy), later modified (from 2005) to $5 \times 5$ Gy irradiation. One patient with a retroperitoneal tumour received $50.4 \mathrm{~Gy}$ in $1.8 \mathrm{~Gy}$ per fraction. Radiation therapy RT was administered after 2 cycles of ifosfamide and surgery was performed within 3-5 days after completing RT. In patients, after an earlier unplanned tumour resection, scar re-excision was performed. Patients were followed at 3-month intervals for 2 years, then at 6-month intervals for 3 years and annually thereafter. As the Common Terminology Criteria for Adverse Events (CTCAE) versions have significantly evolved, the tolerance of adjuvant chemotherapy was evaluated according to the CTCAE version 4.0 (Protocol Amendement 01/2010) [22]. The frequency of complications related to wound healing was also evaluated. Ethical approval for this study was obtained from the ethics committee of Maria Sklodowska-Curie National Research Institute of Oncology on 31 March 2009, code number 34/2009. All participating patients signed an informed consent form.

\section{Statistical Analysis}

Statistical analysis was performed in the language and environment $\mathrm{R}$ (version 3.5.1), using the tidyverse and survminer packages [23,24]. Descriptive analysis was performed by giving the range of values for numerical variables and the percentage distribution for category variables. Survival curves, median survival with the confidence interval and 5- and 10-year survivals were estimated by the Kaplan-Meier method. The comparison of survival curves, particularly patient subgroups (univariate analysis), was performed using the log-rank test. Overall survival (OS) was calculated from the date of 
surgery in the frame of combined therapy to the date of death or the date of the last observation in living patients (censored observations). The starting date was the same for the calculations of local relapse-free survival (LRFS), metastasis-free survival (MFS) and disease-free survival (DFS). The final date (complete observations) for LRFS was the date of the local recurrence, for MFS, the date of finding distant metastases, and for DFS, the date of the first recurrence of the disease after finishing combined treatment. In patients in whom disease recurrence was not observed, the final date was the date of the last observation of the patient (censored observations). The Cox regression proportional hazard model was used to evaluate independent factors affecting the patients' survival. The model encompassed statistically significant variables in univariate analyses as well as the variables which, according to the literature, could affect the patients' prognoses. The statistical significance level was taken as $p \leq 0.05$.

\section{Results}

\subsection{Patients and Treatment}

Patient demographics, tumour characteristics and treatment are summarised in Table 1. The median follow-up was 114 months (range, 3-244 months). The median age of patients was 33 years, with a range of $17-69$. The most common location was lower limb $(n=121)$, followed by upper limb $(n=32)$. Tumours larger than $5 \mathrm{~cm}$ in size were found in $70 \%$ of patients (median $=8 \mathrm{~cm}$ ). The monophasic subtype was more frequent than the biphasic (59\% vs. $33 \%)$. According to the eighth AJCC staging system, 35 (30\%) patients had stage II disease, $55(47 \%)$ patients had stage IIIA disease and $28(24 \%)$ patients had stage IIIB disease. Most patients $(n=149,87 \%)$ received all planned chemotherapy cycles, and most patients received $5 \times 4$ Gy $(n=84,55 \%)$ or $5 \times 5$ Gy $(n=69,43 \%)$ irradiation. The median time from initiating preoperative chemotherapy to the surgery itself was 7 weeks. In the group of patients with SaSy localised in the extremities, limb-sparing surgery was performed in 136 patients (89\%). Negative surgical margins were reported in 149 of 171 (87\%) patients. Adjuvant chemotherapy was discontinued earlier in $11 \%$ of patients. The most frequent reason for discontinuation was the occurrence of adverse events (AEs).

Table 1. Characteristics of patients with locally advanced synovial sarcoma $(n=171)$.

\begin{tabular}{ccc}
\hline Characteristic & $n$ & $\%$ \\
\hline Age & & \\
\hline$\leq 35$ & 102 & 60 \\
$>35$ & 69 & 40 \\
\hline Sex & & \\
\hline Female & 96 & 56 \\
Male & 75 & 44 \\
\hline Histological subtype ${ }^{\text {a }}$ & & \\
\hline Monophasic & 78 & 59 \\
Biphasic & 44 & 33 \\
Poorly differentiated & 11 & 8 \\
\hline Localisation of primary tumour & & \\
\hline Upper limb & 32 & 19 \\
Lower limb & 121 & 71 \\
Trunk wall & 15 & 9 \\
\hline Retroperitoneal space and head and neck & 3 & 2 \\
\hline Size of primary tumour, cm ${ }^{\mathbf{b}}$ & & \\
\hline$\leq 5$ & 35 & 30 \\
\hline 5 & 83 & 70 \\
\hline
\end{tabular}


Table 1. Cont.

\begin{tabular}{|c|c|c|}
\hline Characteristic & $n$ & $\%$ \\
\hline \multicolumn{3}{|l|}{ Disease stage according to $\mathrm{AJCC}^{\mathrm{b}}$} \\
\hline II & 35 & 30 \\
\hline IIIA & 55 & 47 \\
\hline IIIB & 28 & 24 \\
\hline \multicolumn{3}{|l|}{ Status at initiation of treatment in MSCNRIO } \\
\hline Patients previously untreated (primary tumour) & 77 & 45 \\
\hline Patients after surgical treatment without prior diagnostic biopsy & 64 & 37 \\
\hline Clinical local recurrence & 30 & 18 \\
\hline \multicolumn{3}{|l|}{ Type of surgical treatment for localisation in an extremity } \\
\hline Limb-sparing surgery & 136 & 89 \\
\hline Amputation & 17 & 11 \\
\hline \multicolumn{3}{|l|}{ Surgical margins } \\
\hline R0 & 149 & 87 \\
\hline R1 & 22 & 13 \\
\hline Preoperative radiotherapy & 154 & \\
\hline $5 \times 4 G y$ & 84 & 55 \\
\hline $5 \times 5 G y$ & 69 & 45 \\
\hline $28 \times 1.8 \mathrm{~Gy}$ & 1 & 1 \\
\hline \multicolumn{3}{|l|}{ Number of cycles of perioperative adjuvant chemotherapy } \\
\hline $\operatorname{six}$ & 149 & 87 \\
\hline five & 6 & 4 \\
\hline four & 7 & 4 \\
\hline three & 6 & 4 \\
\hline two & 3 & 2 \\
\hline
\end{tabular}

a - In some patients, the data were not included in the histopathological report. ${ }^{b}$-In some patients, the data concerning the primary tumour resected outside the MSCNRIO were not available. MSCRNIO-Maria Sklodowska-Curie National Research Institute of Oncology, AJCC—American Joint Committee on Cancer. Gy_Gray.

\subsection{Local and Distant Recurrence}

Local recurrence occurred in 36 patients (21\%). Median time to local recurrence was 26 months (range, 5-137). The 5- and 10-year LRFS was 80\% (95\% confidence interval (CI) $0.74-0.87$ ) and $74 \%$ (95\% CI 0.66-0.832), respectively. The 5-year LRFS was 93\% in previously untreated patients, $73 \%$ in patients with a resection without a prior diagnostic biopsy and $66 \%$ in patients treated because of a clinical local recurrence. The incidence of local recurrence in patients referred to the Department prior to any surgical treatment was only $8 \%$. Univariate analysis revealed that male sex $(p=0.02)$, R1 resection $(p=0.048)$ and excision of the primary tumour without a prior biopsy $(p<0.001)$ were negative prognostic factors for LRFS (Table 2). In multivariate analysis, only male sex was found to be a statistically significant unfavourable factor for LRFS ( $\mathrm{HR}=2.81, p=0.04)$.

Distant relapse developed in 76 patients (44\%). Median time to distant relapse was 15.5 months. The lungs were the most common site of metastasis $(74 \%)$, followed by the lymph nodes $(13 \%)$. The 5- and 10-year MFS were $60 \%$ (95\% CI 0.53-0.69) and 51\% (95\% CI 0.43-0.60), respectively. Univariate analysis identified age $>35$ years $(p=0.005)$, male sex $(p=0.007)$, T3/T4 stage $(p<0.001)$ and stage III $(p<0.0001)$ as negative prognostic factors for MFS. In multivariate analysis, the statistically significant prognostic factors associated with shorter MFS were age $>35$ years (hazard ratio $(\mathrm{HR})=2.53, p=0.001$ ), histopathological subtype other than monophasic $(\mathrm{HR}=1.95, p=0.021)$ and tumour size as a continuous variable ( $\mathrm{HR}=1.1, p<0.001)$ (Table 3$)$. Since the radiation therapy dosing was modified, we separately analysed the outcome of patients treated in 1997-2004 and 2005-2014 periods. However, there was no statistically significant difference in the LRFS $(p=0.312)$ and MFS $(p=0.666)$ between the two groups. 
Table 2. Univariate analysis of variable factors for LRFS, MFS and OS.

\begin{tabular}{|c|c|c|c|c|c|c|c|c|c|}
\hline Variable & 5-Year LRFS & $95 \% \mathrm{CI}$ & $p$ & 5-Year MFS & $95 \% \mathrm{CI}$ & $p$ & 5-Year OS & $95 \%$ CI & $p$ \\
\hline \multicolumn{10}{|l|}{ Age } \\
\hline$\leq 35$ & $80 \%$ & $0.72-0.89$ & \multirow{2}{*}{0.82} & $66 \%$ & $0.58-0.76$ & \multirow{2}{*}{0.0051} & $81 \%$ & $0.73-0.88$ & \multirow{2}{*}{0.014} \\
\hline$>35$ & $81 \%$ & $0.70-0.93$ & & $52 \%$ & $0.41-0.66$ & & $67 \%$ & $0.57-0.80$ & \\
\hline \multicolumn{10}{|l|}{ Sex } \\
\hline Female & $88 \%$ & $0.81-0.95$ & \multirow{2}{*}{0.02} & $70 \%$ & $0.62-0.81$ & \multirow{2}{*}{0.0068} & $84 \%$ & $0.76-0.92$ & \multirow{2}{*}{$<0.001$} \\
\hline Male & $70 \%$ & $0.59-0.83$ & & $48 \%$ & $0.37-0.61$ & & $64 \%$ & $0.54-0.76$ & \\
\hline \multicolumn{10}{|l|}{ Histological subtype } \\
\hline Monophasic & $78 \%$ & $0.69-0.89$ & \multirow{4}{*}{0.39} & $74 \%$ & $0.64-0.49$ & \multirow{4}{*}{0.08} & $79 \%$ & $0.71-0.89$ & \multirow{4}{*}{0.2} \\
\hline Biphasic & $84 \%$ & $0.73-0.96$ & & $44 \%$ & $0.32-0.62$ & & $60 \%$ & $0.47-0.77$ & \\
\hline Poorly differentiated & $100 \%$ & $1.00-1.00$ & & $50 \%$ & $0.27-0.92$ & & $54 \%$ & $0.26-1.00$ & \\
\hline Not specified & $76 \%$ & $0.63-0.93$ & & $58 \%$ & $0.44-0.76$ & & $65 \%$ & $0.51-0.82$ & \\
\hline \multicolumn{10}{|l|}{ T stage } \\
\hline $\mathrm{T} 1$ & $84 \%$ & $0.71-0.98$ & \multirow{4}{*}{0.97} & $85 \%$ & $0.74-0.98$ & \multirow{4}{*}{$<0.001$} & $88 \%$ & $0.77-0.99$ & \multirow{4}{*}{0.0039} \\
\hline $\mathrm{T} 2$ & $88 \%$ & $0.79-0.98$ & & $53 \%$ & $0.41-0.69$ & & $62 \%$ & $0.50-0.77$ & \\
\hline $\mathrm{T} 3$ & $85 \%$ & $0.71-1.00$ & & $32 \%$ & $0.17-0.61$ & & $51 \%$ & $0.33-0.78$ & \\
\hline $\mathrm{T} 4$ & $86 \%$ & $0.63-1.00$ & & $29 \%$ & $0.09-0.92$ & & $43 \%$ & $0.18-1.00$ & \\
\hline \multicolumn{10}{|l|}{ TNM stage } \\
\hline II & $84 \%$ & $0.71-0.98$ & \multirow{3}{*}{0.86} & $85 \%$ & $0.74-0.98$ & \multirow{3}{*}{$<0.001$} & $88 \%$ & $0.77-0.99$ & \multirow{3}{*}{$<0.001$} \\
\hline IIIA & $88 \%$ & $0.79-0.98$ & & $53 \%$ & $0.41-0.69$ & & $62 \%$ & $0.50-0.77$ & \\
\hline IIIB & $85 \%$ & $0.72-1.00$ & & $28 \%$ & $0.15-0.52$ & & $47 \%$ & $0.31-0.71$ & \\
\hline \multicolumn{10}{|l|}{ Surgical margins } \\
\hline R0 & $82 \%$ & $0.76-0.89$ & \multirow{2}{*}{0.048} & $62 \%$ & $0.55-0.71$ & \multirow{2}{*}{0.57} & $73 \%$ & $0.66-0.81$ & \multirow{2}{*}{0.25} \\
\hline $\mathrm{R} 1$ & $69 \%$ & $0.51-0.93$ & & $50 \%$ & $0.33-0.76$ & & $53 \%$ & $0.35-0.80$ & \\
\hline
\end{tabular}

Abbreviations: CI, confidence interval; LRFS, local recurrence-free survival; MFS, metastatic-free survival; OS, overall survival; TNM (tumour, node, metastasis).

Table 3. Multivariate analysis of variable factors for MFS, DFS and OS.

\begin{tabular}{cccc}
\hline Variables & $\begin{array}{c}\text { MFS } \\
\text { HR (95\% CI), } p\end{array}$ & $\begin{array}{c}\text { DFS } \\
\text { HR (95\% CI), } p\end{array}$ & $\begin{array}{c}\text { OS } \\
\text { HR (95\% CI), } p\end{array}$ \\
\hline Male sex & $1.53(0.90-2.60), p=0.117$ & $1.60(0.97-2.64), p=0.067$ & $2.18(1.25-3.78), p=0.006$ \\
\hline Age $>35$ years & $2.53(1.48-4.34), p=0.001$ & $2.39(1.44-3.96), p=0.001$ & $2.03(1.17-3.52), p=0.012$ \\
\hline $\begin{array}{c}\text { Histologic subtype other } \\
\text { than monophasic }\end{array}$ & $1.95(1.11-3.44), p=0.021$ & $1.97(1.15-3.35), p=0.013$ & $1.94(1.09-3.44), p=0.025$ \\
\hline $\begin{array}{c}\text { Tumour size } \\
\text { (continuous variable) }\end{array}$ & $1.10(1.05-1.16), p<0.001$ & $1.09(1.04-1.14), p<0.001$ & $1.09(1.04-1.14), p<0.001$ \\
\hline
\end{tabular}

Abbreviations: CI, confidence interval; DFS, disease-free survival; HR, hazard ratio; MFS, metastatic-free survival; OS, overall survival.

\subsection{Disease-Free Survival}

The median disease-free survival was 82 months. The 5- and 10-year DFS were $53 \%$ (95\% CI 0.46-0.62) and $47 \%$ (95\% CI (0.40-0.56), respectively (Figure 1). Univariate analysis identified the following negative prognostic factors for DFS: age $>35$ years $(p=0.005)$, male sex $(p=0.03)$, T3/T4 stage $(p<0.001)$ and stage III $(p<0.001)$. In multivariate analysis, the statistically significant prognostic factors associated with shorter DFS age were: $>35$ years $(\mathrm{HR}=2.39, p=0.001)$, histopathological subtype other than monophasic $(\mathrm{HR}=1.97, p=0.013)$ and tumour size as a continuous variable $(\mathrm{HR}=1.09, p<0.001)($ Table 3$)$. 
DFS

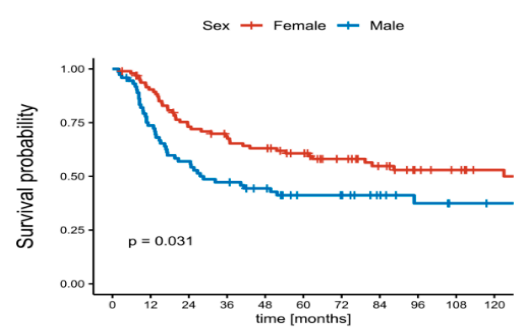

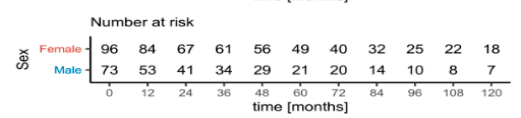

(A)

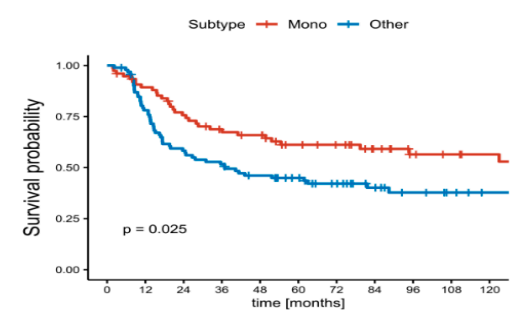

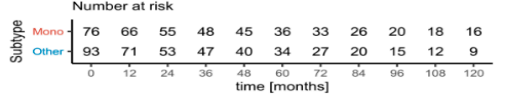

(B)
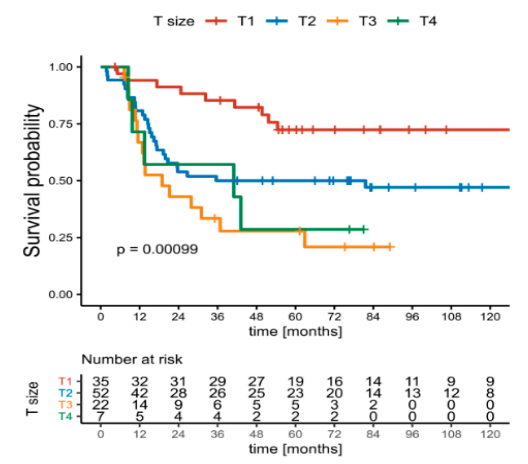

(C)

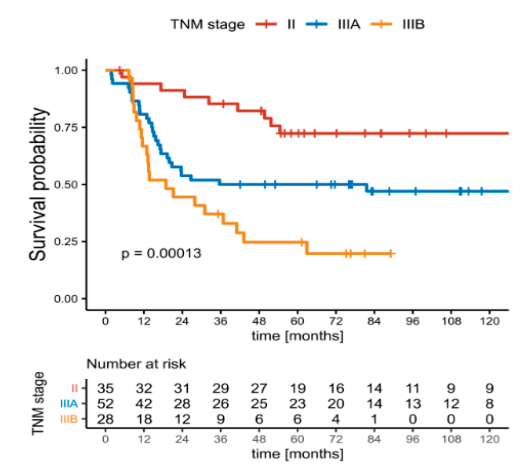

OS
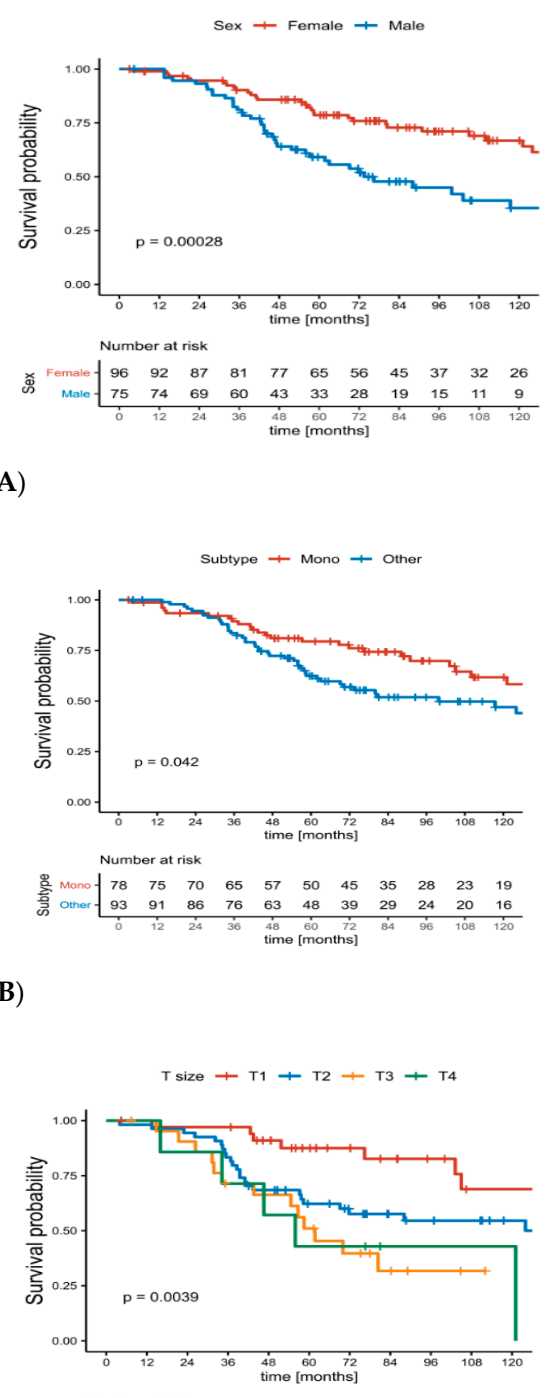

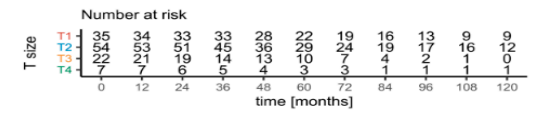

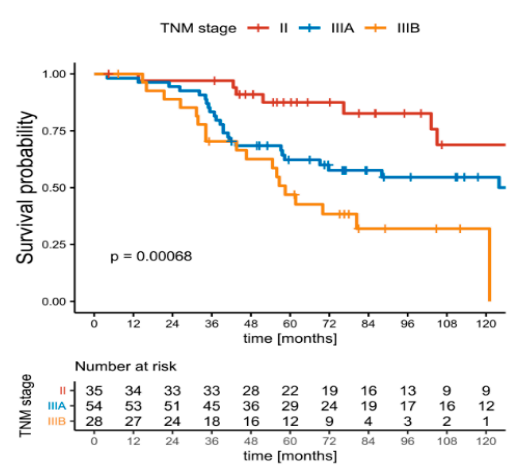

(D)

Figure 1. The curves of disease-free survival (DFS) and overall survival (OS) according to (A) sex, (B) histological subtype, (C) T stage and (D) TNM (tumour, node, metastasis) stage in patients with localised synovial sarcoma. 


\subsection{Overall Survival}

At the final follow-up, 102 patients (60\%) were alive. The 5- and 10 -year OS were $75 \%$ (95\% CI $0.68-0.82)$ and $58 \%(95 \%$ CI $0.51-0.67)$, respectively. The impacts of sex, histological subtype, $\mathrm{T}$ and TNM stage OS and DFS are illustrated in Figure 1. Univariate analysis revealed that male sex $(p<0.001)$, age $>35$ years $(p=0.014)$, T3/T4 stage $(p=0.004)$ and stage III $(p<0.001)$ negatively affected OS. Following multivariate analysis, male sex $(\mathrm{HR}=2.18, p=0.006)$, age $>35$ years $(\mathrm{HR}=2.03, p=0.012)$, a histopathological variant other than monophasic $(\mathrm{HR}=1.94, p=0.025)$ and tumour size as a continuous variable ( $\mathrm{HR}=1.09, p<0.001$ ) were significantly associated with a poor OS (Table 3 ).

\subsection{Safety}

Treatment was completed in 149 of 171 patients $(87 \%)$. The most common reasons for adjuvant chemotherapy discontinuation were wound-healing complications $(n=8,5 \%)$, haematological toxicity $(n=4,2 \%)$, hepatotoxicity $(n=2,1 \%)$ and disease progression $(n=2,1 \%)$. Thirty patients $(18 \%)$ had chemotherapy dose reductions. The most common AEs leading to dose reductions were haematological toxicity $(n=9,5 \%)$, neurotoxicity $(n=8,5 \%)$ and vomiting $(n=7,4 \%)$. Common hematologic AEs graded 3 or higher included neutropenia $(n=42,25 \%)$ and anaemia $(n=11$, $6 \%)$. However, neutropenic fever was reported in only two (1\%) patients. The most frequent non-haematological AEs were nausea $(n=61,36 \%)$, vomiting $(n=37,22 \%)$ and fatigue $(n=35,20 \%)$. Postoperative complications included surgical site infection $(n=43,25 \%)$ and wound dehiscence $(n=26,15 \%)$. No deaths due to toxicity were reported.

\section{Discussion}

STS are a heterogeneous group of tumours with various histological subtypes characterised by different biologic pathways and various treatment sensitivities. SaSy is considered a relatively chemo-sensitive subtype of STS. A review of 15 European Organisation for Research and Treatment of Cancer (EORTC) advanced first-line STS trials concluded that SaSy patients $(n=313)$ had better progression-free survival (median 6.3 vs. 3.7 months), improved OS (median 15 vs. 11.7 months) and a higher response rate $(27.8 \%$ vs. $18.8 \%)$ compared to STS patients. The overall response rate in patients with SaSy was $21.5 \%$ for anthracyclines alone, $32.2 \%$ for doxorubicin in combination with ifosfamide and $33 \%$ for ifosfamide in monotherapy [25]. However, the role of chemotherapy in the adjuvant treatment of SaSy remains unclear. All studies addressing the role of adjuvant treatment in SaSy patients are retrospective analyses and have conflicting results $[2,3,11,17,26,27]$. In two large retrospective studies, no benefit of adjuvant chemotherapy (anthracycline, anthracycline + ifosfamide) was observed [2,3]. In contrast, a single institution analysis published by Chen et al. showed that adjuvant chemotherapy (doxorubicin + ifosfamide or doxorubicin + ifosfamide + dacarbazine) in patients with localised extremity SaSy was associated with a significantly better disease-specific survival (DSS) and MFS in patients with stage IIB and III disease (7th AJCC) [17]. In addition, Vining et al., in an analysis of the data derived from the American National Cancer Database (NCDB), observed that adjuvant chemotherapy was associated with better OS in patients with stage III disease (7th AJCC). The impact of adjuvant chemotherapy on OS in this group of patients was observed both in the univariate (HR 0.56; 95\% CI 0.33-0.93) as well as the multivariate (HR 0.56; 95\% CI 0.33-0.95) analysis [27]. Fewer studies have assessed the role of adjuvant radiotherapy in SaSy patients. Studies from both Surveillance, Epidemiology and End Results (SEER) and NCDB found an overall survival benefit of RT in patients with SaSy undergoing surgery [28,29]. However, two retrospective, single-institution studies demonstrated a significant increase in LRFS with adjuvant RT but no improvement in OS [15,30].

This study was not intended to define the role of adjuvant chemotherapy and radiation therapy in SaSy, because all patients received uniform neo- and adjuvant-combined treatment. Perioperative chemotherapy consisted of four cycles of ifosfamide and two cycles of doxorubicin with cisplatin. In the early 1990s, studies in nonmetastatic STS patients showed high pathologic response rates in patients 
treated with ifosfamide, doxorubicin, cisplatin and irradiation [31]. Our chemotherapy regimen has been developed on the basis of these encouraging results. Currently, doxorubicin with ifosfamide is considered a standard adjuvant regimen in selected high-risk STS patients $[19,20]$. The activity of cisplatin monotherapy in metastatic STS patients has been shown to be minimal but Jelic et al. demonstrated that it can act synergistically with epirubicin [32,33]. Based on the results presented above, we cannot conclude that adding cisplatin had any impact on treatment outcomes.

Nevertheless, the present study indicates that long-term survival can be achieved in this group of patients with high-risk tumours. The 5-year LRFS, MFS and OS were $80 \%, 60 \%$ and $75 \%$, respectively. It is important to note that combined treatment had a favourable safety profile, and the low toxicity of preoperative treatment did not delay surgical resection. Most patients $(87 \%)$ received all planned cycles of chemotherapy. The most common reasons for adjuvant treatment discontinuation were wound-healing complications $(n=8,5 \%)$ and haematological toxicity $(n=4,2 \%)$. Neutropenia at grade $3-4$ was noted in $25 \%$ of patients, and neutropenic fever in $1 \%$ of patients. The results of the largest analyses concerning treatment of patients with localised SaSy published in the last 20 years are presented in Table 4. For comparison, the results of the present analysis, which is the only one to include a uniform scheme of treatment, are included.

Table 4. Comparison of treatment results with the largest analyses concerning treatment of patients with localised synovial sarcoma.

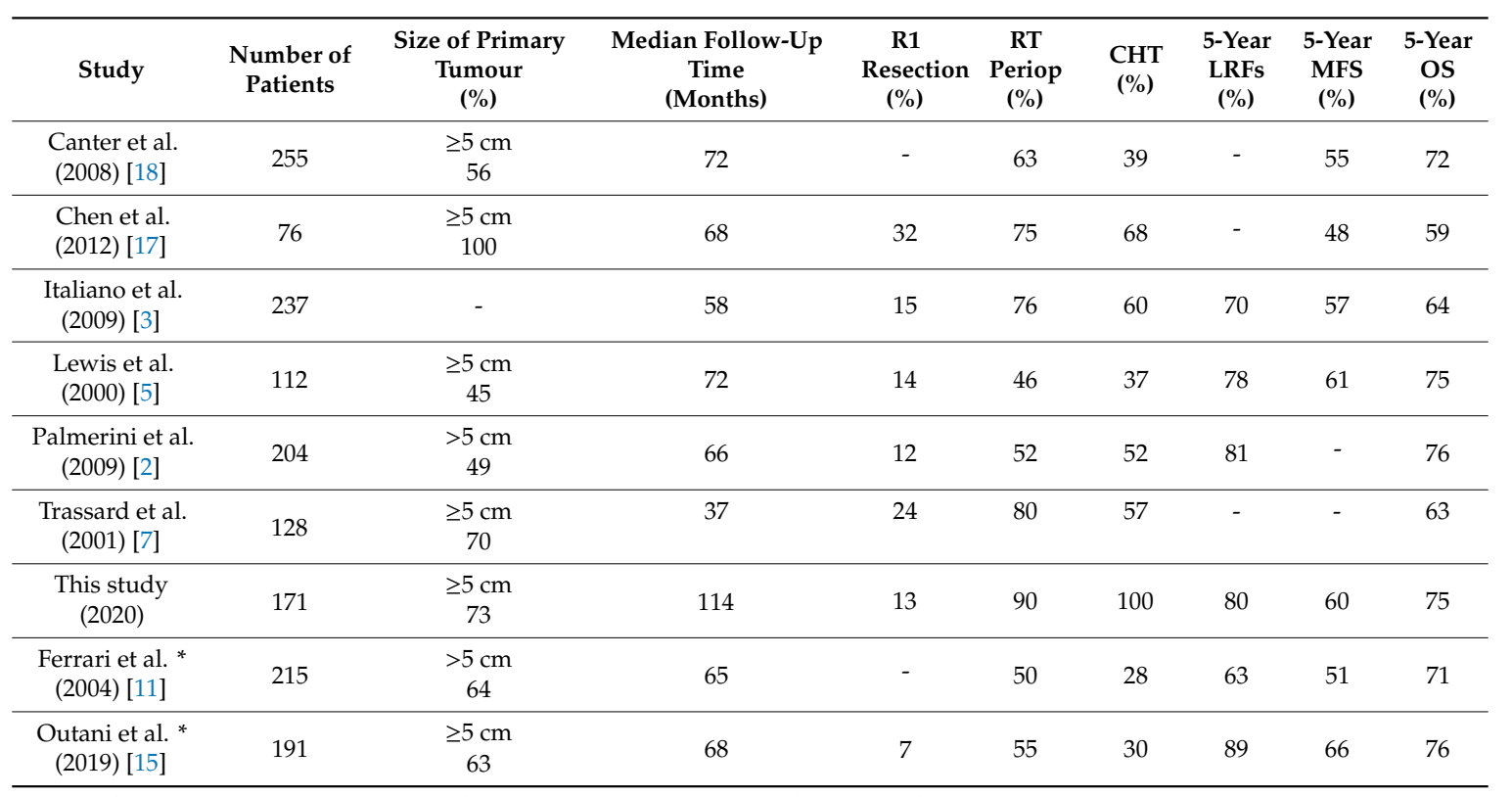

* The analyses encompass both adult patients and children. Abbreviations: CHT, chemotherapy; LRFS, local recurrence-free survival; MFS, metastatic-free survival; OS, overall survival; RT periop, perioperative radiation therapy; -, not reported.

In the literature, a younger age is presented as a favourable prognostic factor for OS in patients with STS [34]. In this study, only patients $\geq 17$ years old were enrolled. The multivariate analysis showed that age $>35$ years was an unfavourable prognostic factor for OS, MFS and DFS. The results also showed a significant correlation between male sex and worse OS. A similar finding has already been reported by Trassard et al. [7].

The prognostic value of histologic subtype in patients with SaSy remains unclear. Most authors associate the worst prognosis with the poorly differentiated subtype, but because of its very rare incidence, it is difficult to demonstrate a statistically significant difference in comparison to the other subtypes [35]. The prognostic significance of the other subtypes has been evaluated in many studies. In most reports, a tendency to better survival was observed in patients with the biphasic subtype in comparison with the monophasic $[2,7,13,16,35]$. Moreover, Vining et al. showed that the biphasic 
subtype was an independent negative prognostic factor for OS (HR 0.41; 95\% CI 0.20-0.83) [27]. In contrast to the reports cited above, the present study's results indicate better outcomes in patients with the monophasic subtype. In the population of patients analysed, the histological subtype was determined in 133/171 patients. The frequency of distribution of particular variants was consistent with the literature data $[2,5,26,27]$. In univariate analyses, the monophasic subtype in comparison to other subtypes was associated with better OS, MFS and DFS. The prognostic value of this finding was confirmed through multivariate analysis. The 5-year OS in patients with monophasic, biphasic and poorly differentiated subtypes were $79 \%, 60 \%$ and $54 \%$, respectively. These results are intriguing, as they show a statistically significant correlation not described previously in the literature. It can therefore be assumed that this observation may be associated with the effect of adjuvant chemotherapy in some of the patients with SaSy.

Primary tumour size is one of the most important prognostic factors in patients with STS. In the present study, the worst outcome was observed in patients with T3 and T4 stage. The 5-year OS was $51 \%$ for $\mathrm{T} 3$ stage and $43 \%$ for $\mathrm{T} 4$ stage. In multivariate analyses, the primary tumour size taken as a continuous variable was a prognostic factor for OS, MFS and DFS but not for LRFS. The impact of the TNM stage on survival in SaSy patients has only been evaluated in several retrospective analyses [6,7]. In the present study, the disease stage was evaluated according to the 8th edition of AJCC [36], which is the first analysis to consider the most recent AJCC classification. In univariate analyses, the TNM stage was a prognostic factor for OS, MFS and DFS. The 5-year OS in stage II, IIIA and IIIB were $88 \%$, $62 \%$ and $47 \%$, respectively. These data indicate that the new AJCC classification clearly differentiates patients with stage IIIA from patients with stage IIIB disease. Poor outcomes in patients with stage IIIB disease underline the need for more intensive treatment in this group of patients or to include them in prospective clinical trials with new therapies.

The role of well-planned surgical resection of the tumour in patients with primary STS is indisputable. One of the largest studies evaluating the importance of proper surgical treatment in patients with STS $(n=375)$ showed that in patients directed to a reference centre after prior surgical treatment, more repeated surgeries were necessary and a higher percentage of local recurrences were observed in comparison with patients treated from the beginning in a reference centre [37]. In the present study, univariate analysis demonstrated that planned surgical treatment was a favourable prognostic factor for LRFS. The 5-year LRFS was significantly better in previously untreated patients than in patients with a resection without a prior diagnostic biopsy (93\% vs. $73 \%$, respectively). The prognostic significance of resection margins in patients with SaSy has been evaluated in numerous retrospective analyses. In univariate analyses, an unfavourable effect of positive margins has been observed on LRFS [6], DSS [7,16] and MFS [5,7]. Moreover, Italiano et al. showed that R1 resection adversely affected OS and LRFS in multivariate analysis [3]. In the present study, local relapse rate was nearly two times higher after R1 resection when compared to R0 resection. The 5-year LRFS in patients after R0 resection in comparison with patients after a microscopically non-radical resection was $82 \%$ and $69 \%(p=0.048)$, respectively. Importantly, the incidence of local recurrence in patients referred to the Department prior to any surgical treatment was only $8 \%$. These findings support the referral of patients with a suspected STS to specialised centres prior to any treatment.

\section{Conclusions}

In conclusion, the results of this study demonstrate long-term survival in adult patients with localised SaSy treated with neo- and adjuvant-combined treatment. The key strengths of this study are the large number of patients included, the uniform mode of treatment and the long period of follow-up. Of note are the positive treatment results obtained despite the high percentage of patients with a primary tumour size larger than $5 \mathrm{~cm}$. These results confirm the importance of planned surgery and clear surgical margins for local control. They suggest that age, sex, disease stage and histological subtype are independent prognostic factors of OS. 
Author Contributions: Conceptualization, K.K. and P.R.; methodology, I.Ł. and P.T.; software, P.T.; validation, P.T.; formal analysis, K.K.; investigation, K.K., T.Ś, H.K.-P., S.F., A.M.C., T.M. and M.W.; resources, K.K., T.Ś., H.K.-P., S.F., A.M.C., T.M. and M.W.; data curation, K.K., T.Ś., H.K.-P., S.F., A.M.C., I.Ł., T.M. and M.W.; writing-original draft preparation, K.K. and E.B.; writing—review and editing, T.Ś., H.K.-P., S.F., M.W. and P.R.; visualization, K.K.; supervision, P.R.; project administration, K.K. and S.F. All authors have read and agreed to the published version of the manuscript.

Funding: This research received no external funding.

Conflicts of Interest: The authors report no conflicts of interest in this work. The abstract of this paper was presented as a poster at the ESMO 2019 Congress in Barcelona, Spain. The abstract was published in "Poster Abstracts" in Annals of Oncology 201930 (suppl_5); https:/oncologypro.esmo.org/meeting-resources/esmo-2019-congress/ The-final-outcomes-of-study-on-combined-therapy-of-adult-patients-with-localized-synovial-sarcoma.

\section{References}

1. Brennan, M.F.; Antonescu, C.R.; Alektiar, K.M.; Maki, R.G. Management of Soft Tissue Sarcoma; Springer: New York, NY, USA, 2013.

2. Palmerini, E.; Staals, E.L.; Alberghini, M.; Zanella, L.; Ferrari, C.; Benassi, M.S.; Picci, P.; Mercuri, M.; Bacci, G.; Ferrari, S. Synovial sarcoma: Retrospective analysis of 250 patients treated at a single institution. Cancer 2009, 115, 2988-2998. [CrossRef] [PubMed]

3. Italiano, A.; Penel, N.; Robin, Y.M.; Bui, B.; Le Cesne, A.; Piperno-Neumann, S.; Tubiana-Hulin, M.; Bompas, E.; Chevreau, C.; Isambert, N.; et al. Neo/adjuvant chemotherapy does not improve outcome in resected primary synovial sarcoma: A study of the French Sarcoma Group. Ann. Oncol. 2009, 20, 425-430. [CrossRef] [PubMed]

4. Eilber, F.C.; Dry, S.M. Diagnosis and management of synovial sarcoma. J. Surg. Oncol. 2008, 97, 314-320. [CrossRef]

5. Lewis, J.J.; Antonescu, C.R.; Leung, D.H.; Blumberg, D.; Healey, J.H.; Woodruff, J.M.; Brennan, M.F. Synovial sarcoma: A multivariate analysis of prognostic factors in 112 patients with primary localized tumors of the extremity. J. Clin. Oncol. 2000, 18, 2087-2094. [CrossRef] [PubMed]

6. Spillane, A.J.; A'Hern, R.; Judson, I.R.; Fisher, C.; Thomas, J.M. Synovial sarcoma: A clinicopathologic, staging, and prognostic assessment. J. Clin. Oncol. 2000, 18, 3794-3803. [CrossRef] [PubMed]

7. Trassard, M.; Le Doussal, V.; Hacene, K.; Terrier, P.; Ranchere, D.; Guillou, L.; Fiche, M.; Collin, F.; Vilain, M.O.; Bertrand, G.; et al. Prognostic factors in localized primary synovial sarcoma: A multicenter study of 128 adult patients. J. Clin. Oncol. 2001, 19, 525-534. [CrossRef] [PubMed]

8. Panagopoulos, I.; Mertens, F.; Isaksson, M.; Limon, J.; Gustafson, P.; Skytting, B.; Akerman, M.; Sciot, R.; Dal Cin, P.; Samson, I.; et al. Clinical impact of molecular and cytogenetic findings in synovial sarcoma. Genes Chromosomes. Cancer 2001, 31, 362-372. [CrossRef]

9. Carmody Soni, E.E.; Schlottman, S.; Erkizan, H.V.; Uren, A.; Toretsky, J.A. Loss of SS18-SSX1 inhibits viability and induces apoptosis in synovial sarcoma. Clin. Orthop. Relat. Res. 2014, 472, 874-882. [CrossRef]

10. Ladanyi, M.; Antonescu, C.R.; Leung, D.H.; Woodruff, J.M.; Kawai, A.; Healey, J.H.; Brennan, M.F.; Bridge, J.A.; Neff, J.R.; Barr, F.G.; et al. Impact of SYT-SSX fusion type on the clinical behavior of synovial sarcoma: A multi-institutional retrospective study of 243 patients. Cancer Res. 2002, 62, 135-140.

11. Ferrari, A.; Gronchi, A.; Casanova, M.; Meazza, C.; Gandola, L.; Collini, P.; Lozza, L.; Bertulli, R.; Olmi, P.; Casali, P.G. Synovial sarcoma: A retrospective analysis of 271 patients of all ages treated at a single institution. Cancer 2004, 101, 627-634. [CrossRef]

12. Gronchi, A.; Ferrari, S.; Quagliuolo, V.; Broto, J.M.; Pousa, A.L.; Grignani, G.; Basso, U.; Blay, J.-Y.; Tendero, O.; Diaz, R.; et al. Histotype-tailored neoadjuvant chemotherapy versus standard chemotherapy in patients with high-risk soft-tissue sarcomas (ISG-STS 1001): An international, open-label, randomised, controlled, phase 3, multicentre trial. Lancet Oncol. 2017, 18, 812-822. [CrossRef]

13. Kawai, A.; Woodruff, J.; Healey, J.H.; Brennan, M.F.; Antonescu, C.R.; Ladanyi, M. SYT-SSX gene fusion as a determinant of morphology and prognosis in synovial sarcoma. N. Engl. J. Med. 1998, 338, $153-160$. [CrossRef] [PubMed]

14. Inagaki, H.; Nagasaka, T.; Otsuka, T.; Sugiura, E.; Nakashima, N.; Eimoto, T. Association of SYT-SSX fusion types with proliferative activity and prognosis in synovial sarcoma. Mod. Pathol. 2000, 13, 482-488. [CrossRef] [PubMed] 
15. Outani, H.; Nakamura, T.; Murata, H.; Stevenson, J.; Parry, M.; Gregory, J.; Tillman, R.; Jeys, L.; Abudu, A. Localized synovial sarcoma: A single institutional study of 191 patients with a minimum follow-up of 5 years for survivors. J. Surg. Oncol. 2019, 119, 850-855. [CrossRef] [PubMed]

16. Singer, S.; Baldini, E.H.; Demetri, G.D.; Fletcher, J.A.; Corson, J.M. Synovial sarcoma: Prognostic significance of tumor size, margin of resection, and mitotic activity for survival. J. Clin. Oncol. 1996, 14, 1201-1208. [CrossRef]

17. Chen, Y.; Yang, Y.; Wang, C.; Shi, Y. Adjuvant chemotherapy decreases and postpones distant metastasis in extremity stage IIB/III synovial sarcoma patients. J. Surg. Oncol. 2012, 106, 162-168. [CrossRef]

18. Canter, R.J.; Qin, L.X.; Maki, R.G.; Brennan, M.F.; Ladanyi, M.; Singer, S. A synovial sarcoma-specific preoperative nomogram supports a survival benefit to ifosfamide-based chemotherapy and improves risk stratification for patients. Clin. Cancer Res. 2008, 14, 8191-8197. [CrossRef]

19. Von Mehren, M.; Benjamin, R.S. Soft Tissue Sarcoma, Version 2.2020, NCCN Clinical Practice Guidelines in Oncology. Available online: https://www.nccn.org/professionals/physician_gls/PDF/sarcoma.pdf (accessed on 27 September 2020).

20. Casali, P.G.; Abecassis, N.; Bauer, S.; Biagini, R.; Bielack, S.; Bonvalot, S.; Boukovinas, I.; Bovee, J.V.M.G.; Brodowicz, T.; Broto, J.M.; et al. Soft tissue and visceral sarcomas: ESMO-EURACAN Clinical Practice Guidelines for diagnosis, treatment and follow-up. Ann. Oncol. 2018, 29, iv51-iv67. [CrossRef]

21. Krieg, A.H.; Hefti, F.; Speth, B.M.; Jundt, G.; Guillou, L.; Exner, U.G.; von Hochstetter, A.R.; Cserhati, M.D.; Fuchs, B.; Mouhsine, E.; et al. Synovial sarcomas usually metastasize after $>5$ years: A multicenter retrospective analysis with minimum follow-up of 10 years for survivors. Ann. Oncol. 2011, 22, 458-467. [CrossRef]

22. U.S. Department of Health and Human Services. Common Terminology Criteria for Adverse Events (CTCAE) Version 4.0; National Cancer Institute: Bethesda, MD, USA, 2009.

23. Team R Core. R: A Language and Environment for Statistical Computing; R Foundation for Statistical Computing: Vienna, Austria, 2017.

24. Wickham, H. Tidyverse: Easily Install and Load "Tidyverse" Packages. 2017. Available online: https: //tidyverse.tidyverse.org/ (accessed on 22 September 2020).

25. Vlenterie, M.; Litiere, S.; Rizzo, E.; Marreaud, S.; Judson, I.; Gelderblom, H.; Le Cesne, A.; Wardelmann, E.; Messiou, C.; Gronchi, A.; et al. Outcome of chemotherapy in advanced synovial sarcoma patients: Review of 15 clinical trials from the European Organisation for Research and Treatment of Cancer Soft Tissue and Bone Sarcoma Group; setting a new landmark for studies in this entity. Eur. J. Cancer 2016, 58, 62-72. [CrossRef]

26. Eilber, F.C.; Brennan, M.F.; Eilber, F.R.; Eckardt, J.J.; Grobmyer, S.R.; Riedel, E.; Forscher, C.; Maki, R.G.; Singer, S. Chemotherapy is associated with improved survival in adult patients with primary extremity synovial sarcoma. Ann. Surg. 2007, 246, 105-113. [CrossRef] [PubMed]

27. Vining, C.C.; Sinnamon, A.J.; Ecker, B.L.; Kelz, R.R.; Fraker, D.L.; Roses, R.E.; Karakousis, G.C. Adjuvant chemotherapy in resectable synovial sarcoma. J. Surg. Oncol. 2017, 116, 550-558. [CrossRef] [PubMed]

28. Naing, K.W.; Monjazeb, A.M.; Li, C.S.; Lee, L.Y.; Yang, A.; Borys, D.; Canter, R.J. Perioperative radiotherapy is associated with improved survival among patients with synovial sarcoma: A SEER analysis. J. Surg. Oncol. 2015, 111, 158-164. [CrossRef] [PubMed]

29. Gingrich, A.A.; Marrufo, A.S.; Liu, Y.; Li, C.S.; Darrow, M.A.; Monjazeb, A.M.; Thorpe, S.W.; Canter, R.J. Radiotherapy is Associated With Improved Survival in Patients With Synovial Sarcoma Undergoing Surgery: A National Cancer Database Analysis. J. Surg. Res. 2020, 255, 378-387. [CrossRef] [PubMed]

30. Song, S.; Park, J.; Kim, H.J.; Kim, I.H.; Han, I.; Kim, H.S.; Kim, S. Effects of Adjuvant Radiotherapy in Patients With Synovial Sarcoma. Am. J. Clin. Oncol. 2017, 40, 306-311. [CrossRef]

31. Eilber, F.; Eckardt, J.; Rosen, G.; Forscher, C.; Selch, M.; Fu, Y.S. Preoperative therapy for soft tissue sarcoma. Hematol. Oncol. Clin. N. Am. 1995, 9, 817-823. [CrossRef]

32. Blay, J.Y.; Papai, Z.; Tolcher, A.W.; Italiano, A.; Cupissol, D.; López-Pousa, A.; Chawla, S.P.; Bompas, E.; Babovic, N.; Penel, N.; et al. Ombrabulin plus cisplatin versus placebo plus cisplatin in patients with advanced soft-tissue sarcomas after failure of anthracycline and ifosfamide chemotherapy: A randomised, double-blind, placebo-controlled, phase 3 trial. Lancet Oncol. 2015, 16, 531-540. [CrossRef]

33. Jelic, S.; Kovcin, V.; Milanovic, N.; Babovic, N.; Kreacic, M.; Ristovic, Z.; Vlajic, M.; Filipovic-Ljeskovic, I. Randomized study of high-dose epirubicin versus high-dose epirubicin and cisplatin chemotherapy for advanced soft tissue sarcoma. Eur. J. Cancer 1997, 33, 220-225. [CrossRef] 
34. Ferrari, A.; Sultan, I.; Huang, T.T.; Rodriguez-Galindo, C.; Shehadeh, A.; Meazza, C.; Ness, K.K.; Casanova, M.; Spunt, S.L. Soft tissue sarcoma across the age spectrum: A population-based study from the Surveillance Epidemiology and End Results database. Pediatr. Blood Cancer 2011, 57, 943-949. [CrossRef]

35. Guillou, L.; Benhattar, J.; Bonichon, F.; Gallagher, G.; Terrier, P.; Stauffer, E.; de Saint Aubain Somerhausen, N.; Michels, J.J.; Jundt, G.; Vince, D.R.; et al. Histologic grade, but not SYT-SSX fusion type, is an important prognostic factor in patients with synovial sarcoma: A multicenter, retrospective analysis. J. Clin. Oncol. 2004, 22, 4040-4050. [CrossRef]

36. Amin, M.B.; Edge, S.; Greene, F.; Byrd, F.; Brookland, D.R.; Washington, R.K.; Gershenwald, J.E.; Compton, C.C.; Hess, K.R.; Sullivan, D.C.; et al. (Eds.) AJCC Cancer Staging Manual, 8th ed.; Springer International Publishing: Cham, Switzerland, 2017.

37. Gustafson, P.; Dreinhofer, K.E.; Rydholm, A. Soft tissue sarcoma should be treated at a tumor center. A comparison of quality of surgery in 375 patients. Acta Orthop. Scand. 1994, 65, 47-50. [CrossRef] [PubMed]

(C) 2020 by the authors. Licensee MDPI, Basel, Switzerland. This article is an open access article distributed under the terms and conditions of the Creative Commons Attribution (CC BY) license (http://creativecommons.org/licenses/by/4.0/). 